\title{
Sources and Abbreviations
}

Sources cited as "unpublished" in notes and bibliography are materials provided to me by their authors or by other persons who cooperated in my research. All such papers are in my possession.

$\begin{array}{ll}\text { AA } & \text { American Anthropologist } \\ \text { AI } & \text { Akty istoricheskie } \\ \text { ArA } & \text { Arctic Anthropology } \\ \text { DAI } & \text { Dopolneniia k aktam istoricheskim } \\ \text { E } & \text { Etnografiia } \\ \text { HRAF } & \text { Human Relations Area File } \\ \text { IG } & \text { Izvestiia GAIMK } \\ \text { IM } & \text { Istorik-marksist } \\ \text { IRGO } & \text { Imperatorskoe russkoe geograficheskoe } \\ & \text { obshchestvo } \\ \text { IV } & \text { Istoricheskii viestnik } \\ \text { MS } & \text { Morskoi sbornik } \\ \text { OPS } & \text { Okhotnik i pushnik Sibiri } \\ \text { ORS } & \text { Okhotnik i rybak Sibiri } \\ \text { OS } & \text { Okhotnik Sibiri } \\ \text { P } & \text { Pedologiia } \\ \text { PB } & \text { Pravoslavnyi blagoviestnik } \\ \text { PN } & \text { Prosveshchenie natsional'nostei } \\ \text { PS } & \text { Partiinoe stroitel'stvo } \\ \text { PSI } & \text { Pamiatniki sibirskoi istorii } \\ \text { PSRL } & \text { Polnoe sobranie russkikh letopisei, 1962- } \\ \text { PSZ } & \text { Polnoe sobranie zakonov Rossiiskoi imperii } \\ \text { RA } & \text { Russkii arkhiv } \\ \text { RIB } & \text { Russkaia istoricheskaia biblioteka } \\ \text { RN } & \text { Revoliutsiia i natsional'nosti } \\ \text { RV } & \text { Russkii viestnik }\end{array}$


xiv Sources And Abbreviations

SA Sovetskaia (Severnaia) Aziia

SAr Sovetskaia Arktika

$S E$

Sovetskaia etnografiia

SEER

Slavonic and East European Review

SO

SP

Sibirskie ogni

Severnye prostory

SR Slavic Review

SS Sovetskii sever

SSb Sibirskii sbornik

TsGAOR Tsentral'nyi gosudarstvennyi arkhiv Oktiabr'skoi revoliutsii, Moscow, Russia

TT Taiga i tundra

VK Voprosy kolonizatsii

ZhMNP Zhurnal Ministerstva narodnogo prosveshcheniia

ZhN

ZhS

Zhizn' natsional'nostei

Zhivaia starina 


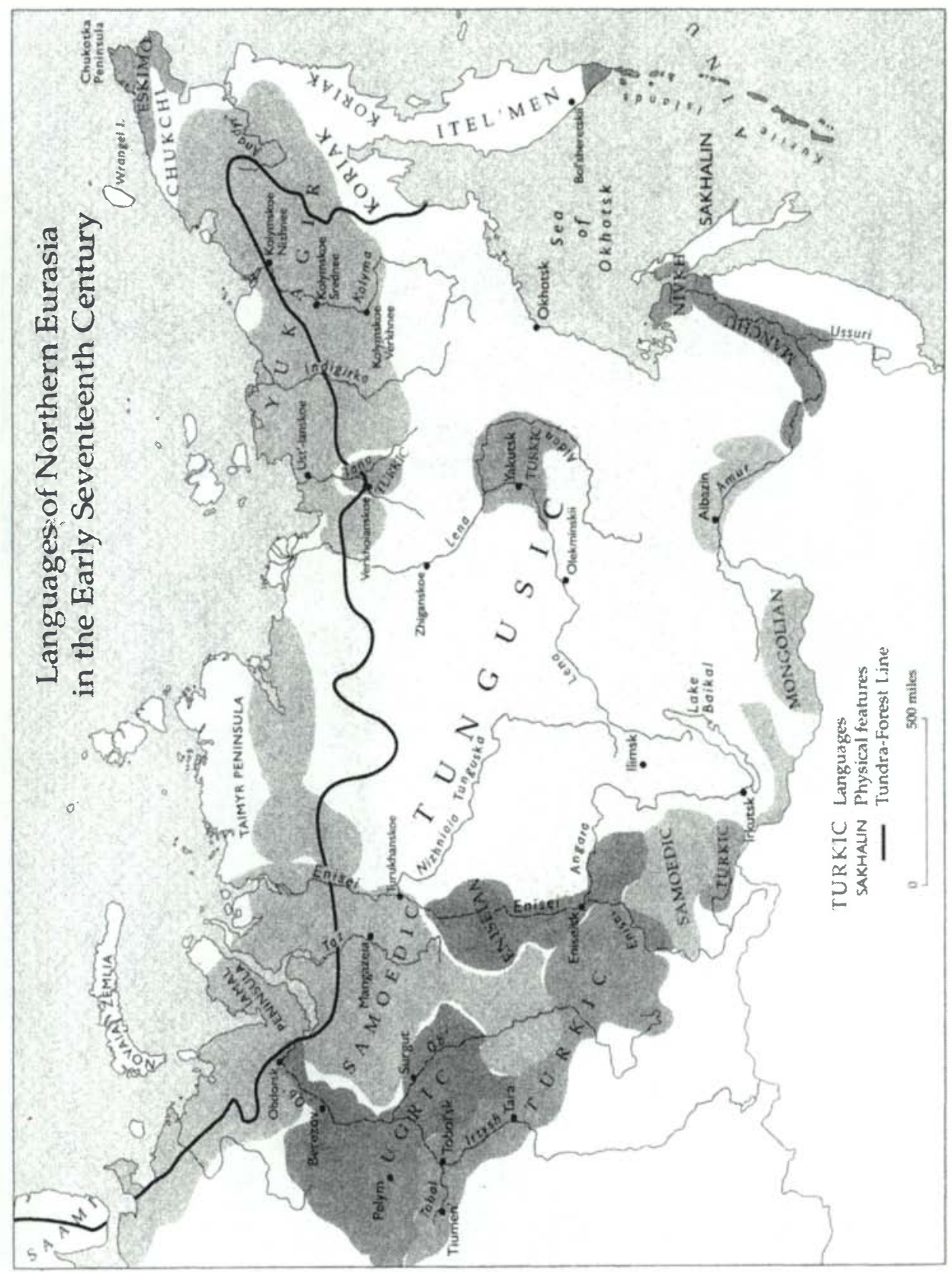




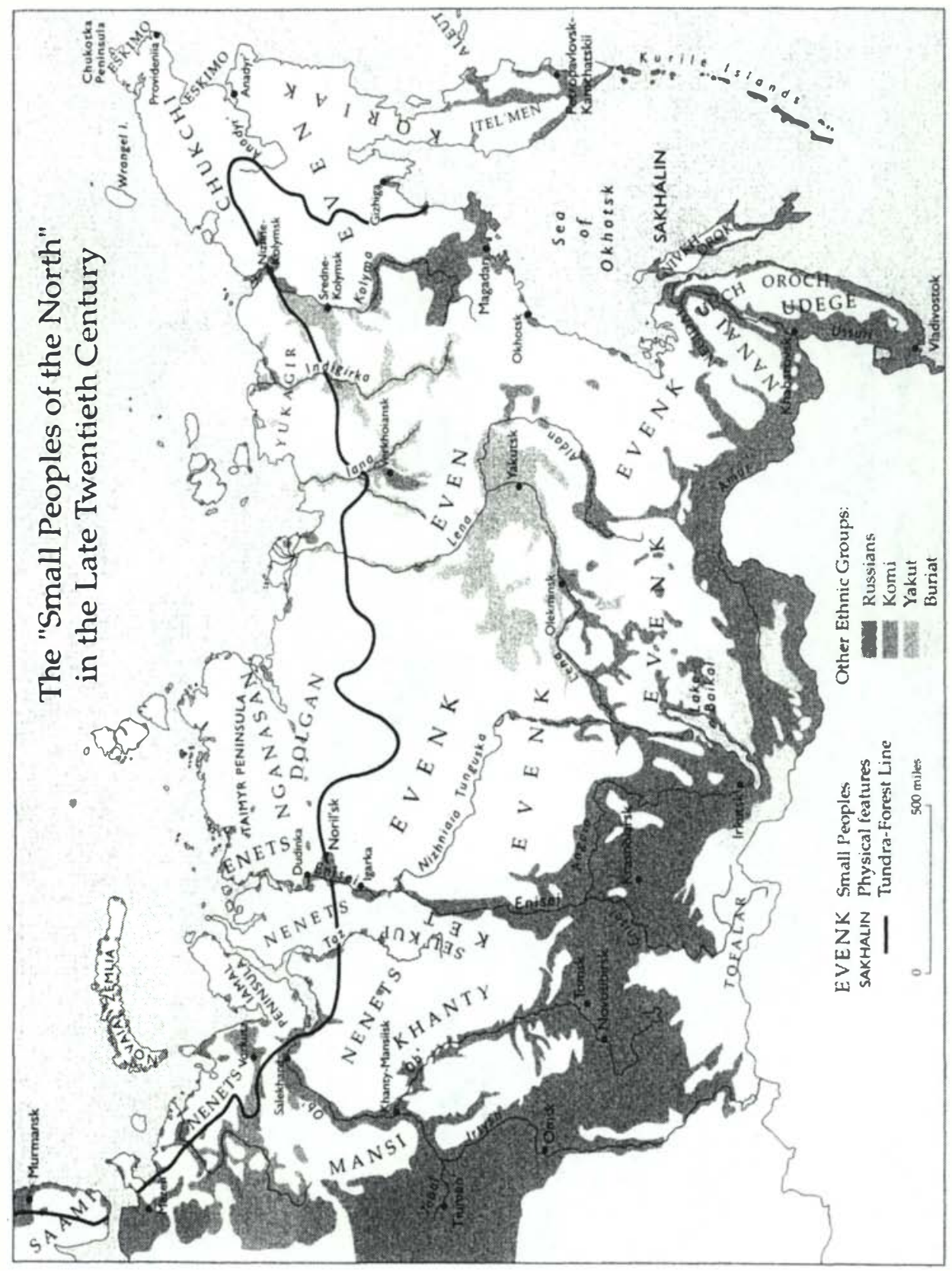


ARCTIC MIRRORS 
